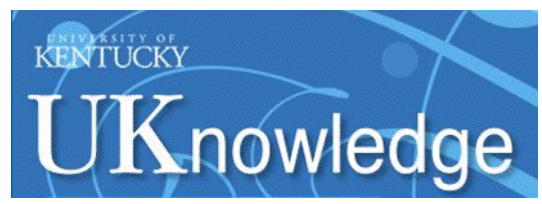

University of Kentucky

UKnowledge

\title{
Ethnic Disparities in Cervical Cancer Survival Among Medicare Eligible Women in a Multiethnic Population
}

\author{
Ann L. Coker \\ University of Kentucky, ann.coker@uky.edu \\ Katherine S. Eggleston \\ University of Texas Health Science Center at Houston \\ Xianglin L. Du \\ University of Texas Health Science Center at Houston, xianglin.I.du@uth.tmc.edu \\ Lois Ramondetta \\ University of Texas M.D. Anderson Cancer Center, Iramonde@mdanderson.org
}

Follow this and additional works at: https://uknowledge.uky.edu/crvaw_facpub

Part of the Obstetrics and Gynecology Commons, Public Health Commons, Social Work Commons, and the Sociology Commons

Right click to open a feedback form in a new tab to let us know how this document benefits you.

\section{Repository Citation}

Coker, Ann L.; Eggleston, Katherine S.; Du, Xianglin L.; and Ramondetta, Lois, "Ethnic Disparities in Cervical Cancer Survival Among Medicare Eligible Women in a Multiethnic Population" (2009). CRVAW Faculty Journal Articles. 141.

https://uknowledge.uky.edu/crvaw_facpub/141

This Article is brought to you for free and open access by the Center for Research on Violence Against Women at UKnowledge. It has been accepted for inclusion in CRVAW Faculty Journal Articles by an authorized administrator of UKnowledge. For more information, please contact UKnowledge@lsv.uky.edu. 
Ethnic Disparities in Cervical Cancer Survival Among Medicare Eligible Women in a Multiethnic Population

Digital Object Identifier (DOI)

http://dx.doi.org/10.1111/IGC.0b013e318197f343

Notes/Citation Information

This manuscript provided with permission from the publisher, and also accessible through the journal's website at http://journals.Iww.com/ijgc/Abstract/2009/01000/

Ethnic_Disparities_in_Cervical_Cancer_Survival.4.aspx. 


\title{
Ethnic Disparities in Cervical Cancer Survival Among Medicare Eligible Women in a Multiethnic Population
}

\author{
Ann L. Coker, PhD, * Katherine S. Eggleston, MSPH, $\dagger$ \\ Xianglin L. Du, MD, PhD, $\dagger$ and Lois Ramondetta, MD $\ddagger$
}

\begin{abstract}
Objectives: To determine predictors of cervical cancer survival by socioeconomic status (SES), urbanization, race/ethnicity, comorbid conditions, and treatment among elderly Medicare-eligible women whose conditions were diagnosed with cervical cancer in a multiethnic population.

Methods: A total of 538 women with cervical cancer aged 65 years or older were identified from 1999 to 2001 from the Texas Cancer Registry and were linked with the state Medicare data and Texas Vital Records to determine survival times. All women had similar access to care through Medicare fee-for-services insurance. A composite measure of SES was created using census tract-level data as was urbanization. Treatment and comorbid conditions were available from the Medicare data. Cox proportional hazards modeling was used for all-cause and cervical cancer-specific survival analysis.

Results: Increased age $(P<0.0001)$ and advanced tumor stage $(P<0.0001)$ were associated with poorer allcause and cervical cancer-specific survival. Having a comorbid condition was associated with all-cause survival $(P<0.01)$ but not cervical cancer-specific mortality. After adjusting for confounders, women receiving some form of treatment were almost half as likely to die with cervical cancer (adjusted hazard ratio $=0.68 ; 95 \%$ confidence interval, 0.52-0.89). After adjustment for all confounders, Hispanic women consistently had lower all-cause and cervical cancer-specific mortality rates relative to non-Hispanic white and non-Hispanic black women.

Conclusions: Among women with similar health care coverage, Hispanic women had consistently lower all-cause and cervical cancer-specific mortality rates than other older women whose conditions were diagnosed with this disease in Texas. The presence of comorbid conditions and treatment were important predictors of survival, yet these factors do not explain the survival advantage for Hispanic women.
\end{abstract}

Key Words: Race, Ethnicity, Cervical neoplasia, Survival, Medicare, Elderly, Socioeconomic status, Comorbid conditions, Treatment

(Int J Gynecol Cancer 2009;19: 13-20)

Porrong oorer survival rates among minority populations whose conditions were diagnosed with cervical cancer have been well documented, ${ }^{1}$ although the reason for this disparity of poorer outcomes remains unclear. Differences in stage at diagnosis, number of comorbid conditions, timeliness of treatment received, age, urbanization, and socioeconomic status (SES) may explain this survival disparity. Newmann and Garner ${ }^{2}$ conclude in their meta-analysis that social inequality, defined by race and SES, is associated with an increased risk of cervical cancer incidence, yet social inequities have not been consistently established as independent risk factors for poorer cervical cancer survival. Of the 17 studies with at least 100 cervical cancer cases, ${ }^{3-19} 7$ found that race/ethnicity remained associated with poorer survival after adjusting for age, ${ }^{4}$

*School of Medicine, University of Kentucky, Lexington, KY; †School of Public Health, University of Texas Health Science Center, Houston, TX; †Department of Gynecologic Oncology, University of Texas MD Anderson Cancer Center, Houston, TX.

Address correspondence and reprint requests to Ann L. Coker, PhD, School of Medicine, University of Kentucky, 800 Rose St, C-371, Lexington, KY 40536-0293. E-mail: ann.coker@uky.edu.

Copyright $₫ 2009$ by IGCS and ESGO

ISSN: $1048-891 \mathrm{X}$

DOI: 10.1111/IGC.0b013e318197f343 stage, ${ }^{8}$ SES, ${ }^{7,19}$ and treatment. ${ }^{3,6,9}$ The evolving literature addressing proxy measures of SES and survival is more consistent. Six $^{10,12,13,19-21}$ of the 11 studies $^{7,10,12,13,18-21}$ find that lower SES is associated with poorer survival when adjusting for age, stage, tumor characteristics, and race. Two large studies conducted among those with similar access to health care found that $\mathrm{SES}^{18}$ and race ${ }^{14}$ were not associated with survival. Although age is an important factor for survival after a cervical cancer diagnosis, existing studies are mixed in finding that increasing age is associated with poorer survival after controlling for confounders. ${ }^{3-5,8-10,13,22-36}$ Few studies have addressed the patterns of care and survival among elderly women. ${ }^{18,24}$

The purpose of this study was to estimate cervical cancer survival by demographic factors, comorbidities, and treatment among women aged 65 years and older whose conditions were diagnosed with cervical cancer and were reported to the Texas Cancer Registry (TCR). All women included in this analysis were Medicare-eligible based on age alone (aged $\geq 65$ years).

\section{METHODS}

\section{Study Population and Data Sources}

We conducted a population-based survival analysis among women aged 65 years and older whose conditions were diagnosed 
with cervical cancer and were reported to the TCR from 1999 to 2001. Institutional review boards from the Texas Department of State Health Services and the University of Texas Health Science Center at Houston approved the study protocol. These dates were selected because these were the most recent Medicare and TCR data available at the time the study was funded. Data from Texas Vital Records were used to determine survival dates and cause of death. Only invasive cervical cancer cases were included in this analysis; carcinoma in situ cases were excluded by the TCR. All cancer cases were geocoded to the block group level based on the address given at the time of diagnosis. This cohort of cervical cancer cases was then merged using social security numbers with Texas Medicare files from 1999 to 2001. Medicare claims files included the denominator record of all enrolled participants, Medicare provider analysis file, outpatient, and inpatient claims records. Medicare data provided information on whether treatment was received, on the type and timing of treatment, and on the number of comorbid conditions.

\section{Demographic Attributes}

Data from the TCR, originally abstracted from medical records, were used to define age at diagnosis, race/ethnicity, stage at diagnosis, and cancer cell type. Race/ethnicity was classified using both race and Spanish/Hispanic origin and comprised the following categories: non-Hispanic white, non-Hispanic black, and Hispanic. The TCR uses SEER summary staging, which was then categorized for analysis as follows: early (stage 1), late (stages 2-7), and unknown stage (stage 9). Cervical cancer cell types were grouped as squamous and nonsquamous owing to established differences in cancer prognosis. No smoking data are available from both Medicare and TCR.

\section{Neighborhood SES and Urbanization}

The following block group-level data from the United States 2000 were used as indicators of neighborhood SES: median household income, proportion below poverty, proportion with a college education, proportion with a management/professional occupation, and median home value. Principal factor analysis was performed to retain one factor representing a composite SES, which was then categorized into tertiles based on the distribution in the Texas population. This methodology has been supported and used in previous health research. ${ }^{37-39}$ The Rural Urban Commuting Area Codes, which use population density, urbanization, and daily commuting, available at the census track level, were used to define aggregate levels of urbanization. ${ }^{40}$ Categorization A, which approximates the metro/nonmetro split at the census track level, was used to describe the data. ${ }^{41}$ The following categories were used: urban focused, large town, small/isolated town.

\section{Comorbid Conditions}

On the basis of an accepted measure of comorbidity, ${ }^{42}$ comorbid conditions were identified from Medicare claims files and corresponded to diagnoses made or procedures consequent to comorbidities in the year before the cervical cancer diagnosis. Two comorbidity indexes were used: the Charlson Index ${ }^{43}$ and the count of number of unique diagnosis codes, ${ }^{44}$ with modifications suggested by Fleming et $\mathrm{al}^{45}$ to provide a comprehensive index for women. The Charlson Index is a weighted count of a range of conditions diagnosed within 1 year of the cervical cancer. These conditions include heart disease, other cancers, hypertension, diabetes, stroke, other vascular disease, chronic obstructive pulmonary disease, dementias, moderate to severe liver disease, chronic renal failure, and ulcers. The higher the index score, the more severe the burden of comorbidity. Anemia (International Classification of Dis- eases, Ninth Revision [ICD-9], 280-285) diagnosed within 30 days of cervical cancer was also included as a specific condition, which, although not necessarily comorbid to cervical cancer, may influence survival.

\section{Treatment}

Data corresponding to treatment received were abstracted from Medicare outpatient, inpatient, and physician claim files. Potential treatments included conization of the cervix, surgery (hysterectomy), chemotherapy, and/or radiation as indicated in the guidelines by the National Cancer Institute for cancers staged I to IV5. The following codes were used to define cone, chemotherapy, surgery, and radiation. Cone: $I C D-9$ procedure codes $(67.2,67.3$, $67.32,67.33)$ and Common procedure codes $(57520,57522,57510$, 57511, 57513). Chemotherapy: ICD-9 procedure codes (9925), ICD-9 diagnostic codes (V58.1, V66.2, V67.2), Common procedure codes (96400-96549, J9000-J9999, Q0083-Q0085), and Revenue center codes $(0331,0332,0335)$. Radiation therapy: $I C D-9$ procedure codes (9221-9229), ICD-9 diagnostic codes (V58.0, V67.1), Common procedure codes (77401-77499, 77750-77799), and Revenue center codes $(0330,0333)$. Surgery: $I C D-9$ procedure codes $(68.3-68.9)$ and Common procedure codes $(51925,56308,58150,58152,58200$, 58180, 58210, 58240, 58260-58270, 58275, 58280, 58285).

Treatment included any claim containing the equivalent diagnostic, procedure, and/or revenue center codes dated 6 months before diagnosis (to allow for lag time in cancer reporting) and up to 1 year after diagnosis. Information on the type of hospital or facility where treatment was received was not available. Dichotomous variables were created indicating (1) any treatment compared with no treatment; (2) surgery (primarily hysterectomy or cone biopsy); (3) radiation or chemotherapy alone; (4) radiation and chemotherapy alone; (5) radiation, chemotherapy, and surgery; and (6) surgery and radiation or chemotherapy. Because we are using claims data, we have no information on treatment delays or the completeness of treatment series. Logistic regression analysis in STATA was performed to assess multivariate predictors of receiving any treatment, as well as individual treatment options.

\section{Cancer Survival}

Information on date and cause of death was available from Texas Vital Statistics Bureau for all diagnosed cancer cases through December 2003. Survival days were calculated based on the diagnosis date (available from TCR data) and the corresponding date of death; those who were still surviving at the end of the followup period were censored in subsequent survival analysis (all-cause and cervical cancer-specific). Survival follow-up times were accrued through December 2003 and ranged from 0 to 1825 days.

\section{Statistical Analysis}

From 1999 to 2001, 688 cases of cervical cancer among women aged 65 years and older were reported to the TCR. Of these cases, 604 had a corresponding record of enrollment in Medicare during the same period. One case was excluded because of inadequate geocoding information to determine SES and urbanization. The average time to treatment in this sample was 27.20 days; thus, to allow adequate time for treatment, an additional 47 cases were excluded diagnosed between October 1, 2001, and December 31, $2001(\mathrm{n}=556)$. Cases with unknown race/ethnicity were also excluded from analysis $(\mathrm{n}=18)$. The final sample size for analysis was 538. Logistic regression was used to determine correlates of receiving any type of treatment within 12 months.

Cox proportional hazards modeling was used to estimate the relative rate of dying from any cause as well as cervical cancer among those whose conditions were diagnosed with this disease 
from 1999 to 2001. Deaths identified through the death certificate alone $(\mathrm{n}=47)$ were excluded, resulting in a survival analysis of 491 women. To better evaluate the effect of race/ethnicity, sociodemographic factors, comorbid conditions, and treatment on survival, we included all factors in one model with time to death as the outcome. The treatment variables included 6 dichotomous variables indicating the type and combination of treatment received. The number of chemotherapy and/or cycles of radiation received was also included in the model. We also created a dichotomous variable indicating whether the woman received any treatment (yes vs no). The multivariate model used was a semiparametric regression modeling procedure describing the risk relationship between survival time and predictor variables and assumed that the underlying hazard rate is a function of the covariates. No assump- tions were made about the nature or shape of the hazard function. All data were analyzed using STATA Version 9.

\section{RESULTS}

Table 1 presents the demographic attributes by race/ethnicity, stage at diagnosis, cervical cancer cell type, number of comorbid conditions, and treatment received by type. The mean (SD) age at diagnosis for this cohort of women aged 65 years and older diagnosed with cervical cancer was 76.0 (7.9) years and ranged from 65 to 103 years. Although $92 \%$ of this cohort had a Medicare claim in the period under study, $31 \%$ had claim indicating treatment. Non-Hispanic black and Hispanic cervical cancer cases were significantly more likely to reside in lower SES neighborhoods relative to non-Hispanic white cases.

TABLE 1. Demographic characteristics of women aged 65 years and older whose conditions were diagnosed with cervical cancer and reported to the TCR from 1999 to 2001 using Medicare-linked treatment data

\begin{tabular}{|c|c|c|c|c|}
\hline $\begin{array}{l}\text { Individual-level } \\
\text { characteristics }\end{array}$ & $\begin{array}{c}\text { All women } \\
(\mathrm{n}=\mathbf{5 3 8}), \mathrm{n}(\%)\end{array}$ & $\begin{array}{l}\text { Non-hispanic white } \\
(\mathrm{n}=304), \mathrm{n}(\%)\end{array}$ & $\begin{array}{l}\text { Non-hispanic black } \\
\quad(\mathrm{n}=99), \mathrm{n}(\%)\end{array}$ & $\begin{array}{c}\text { Hispanic } \\
(\mathrm{n}=135), \mathrm{n}(\%)\end{array}$ \\
\hline \multicolumn{5}{|l|}{ Neighborhood SES* } \\
\hline SES high & $136(25.3)$ & $103(33.9)$ & $16(16.2)$ & $17(12.6)$ \\
\hline SES intermediate & $166(30.9)$ & $114(37.5)$ & $24(24.2)$ & $28(20.7)$ \\
\hline SES low & $236(43.8)$ & $87(28.6)$ & $59(59.6)$ & $90(66.7)$ \\
\hline \multicolumn{5}{|l|}{ Urbanization } \\
\hline Urban & 418 (77.7) & $230(75.6)$ & $79(79.8)$ & $109(80.7)$ \\
\hline Large town & $62(11.5)$ & $34(11.2)$ & $9(9.1)$ & $19(14.1)$ \\
\hline Small town/rural & $58(10.8)$ & $40(13.2)$ & $11(11.1)$ & $7(5.2)$ \\
\hline \multicolumn{5}{|l|}{ Cell type } \\
\hline Squamous carcinomas & $424(78.8)$ & $232(76.3)$ & $79(79.8)$ & $113(83.7)$ \\
\hline Nonsquamous & $114(21.2)$ & $72(23.7$ & $20(20.2)$ & $22(16.3)$ \\
\hline \multicolumn{5}{|l|}{ Stage at diagnosis } \\
\hline Localized & $179(33.3)$ & $109(35.9)$ & $28(28.3)$ & $42(31.1)$ \\
\hline Regional/distant & $219(40.7)$ & $114(37.5)$ & $47(47.5)$ & $58(43.0)$ \\
\hline Unstaged/unknown & $140(26.0)$ & $81(26.64)$ & $24(24.2)$ & $35(25.9)$ \\
\hline \multicolumn{5}{|l|}{ Comorbid conditions } \\
\hline None & $339(63.0)$ & $195(64.1)$ & $61(61.6)$ & $83(61.5)$ \\
\hline One & $112(20.8)$ & $68(22.4)$ & $17(17.2)$ & $27(20.0)$ \\
\hline Two or more & $87(16.2)$ & $41(13.5)$ & $21(21.2)$ & $25(18.5)$ \\
\hline \multicolumn{5}{|l|}{ Medicare claim (1999-2001) } \\
\hline No claim & $44(8.2)$ & $32(10.5)$ & $6(6.1)$ & $6(4.4)$ \\
\hline Claim & $494(91.8)$ & $272(89.5)$ & $93(93.9)$ & $129(95.6)$ \\
\hline \multicolumn{5}{|l|}{ Treatment $\dagger$} \\
\hline No treatment received & $166(30.86)$ & $99(32.6)$ & $33(33.3)$ & $34(25.2)$ \\
\hline Treatment received & $372(69.14)$ & $205(67.4)$ & $66(66.7)$ & $101(74.8)$ \\
\hline \multicolumn{5}{|l|}{ All treatments received } \\
\hline No treatment & $166(30.86)$ & 99 (32.57) & $33(33.33)$ & $34(25.19)$ \\
\hline Surgery/cone alone & $50(9.29)$ & $33(10.86)$ & $7(7.07)$ & $10(7.41)$ \\
\hline Radiation/chemotherapy alone & $81(15.06)$ & $43(14.14)$ & $15(15.15)$ & $23(15.56)$ \\
\hline Radiation and chemotherapy & $85(15.80)$ & $41(13.49)$ & $11(11.11)$ & $33(23.7)$ \\
\hline Radiation, chemotherapy, and surgery & $64(11.90)$ & $39(12.83)$ & $10(10.10)$ & $15(12.59)$ \\
\hline Radiation/chemotherapy and surgery & $92(17.10)$ & $49(16.12)$ & $23(23.23)$ & $20(15.55)$ \\
\hline
\end{tabular}


TABLE 2. Multivariate predictors of treatment received for women aged 65 years and older whose conditions were diagnosed with cervical cancer and reported to the TCR from 1999 to 2001 using Medicare-linked treatment data

\begin{tabular}{|c|c|c|c|}
\hline & $\mathbf{n}$ & $\begin{array}{l}\text { \% Received } \\
\text { treatment* }\end{array}$ & $\begin{array}{l}\text { Odds ratio } \\
(95 \% \mathrm{CI}) \dagger\end{array}$ \\
\hline Age (continuous) & 538 & 69.1 & $0.97(0.94-0.99) \ddagger$ \\
\hline \multicolumn{4}{|l|}{ Race/ethnicity } \\
\hline Non-Hispanic white & 304 & 67.1 & 1.0 REF \\
\hline Non-Hispanic black & 99 & 66.7 & $0.87(0.51-1.49)$ \\
\hline Hispanic & 135 & 74.8 & $1.24(0.73-2.10)$ \\
\hline \multicolumn{4}{|l|}{ Stage at diagnosis } \\
\hline Early & 179 & 77.1 & 1.0 REF \\
\hline Late & 219 & 77.2 & $0.96(0.59-1.56)$ \\
\hline Unknown & 140 & 46.4 & $0.24(0.14-0.40) \ddagger$ \\
\hline \multicolumn{4}{|l|}{ Cell type } \\
\hline Nonsquamous & 114 & 76.3 & $1.23(0.74-2.10)$ \\
\hline Squamous cell & 424 & 67.2 & $1.0 \mathrm{REF}$ \\
\hline \multicolumn{4}{|l|}{ SES $\S$} \\
\hline High SES & 136 & 61.8 & 1.0 REF \\
\hline Mid SES & 166 & 71.7 & $1.49(0.88-2.52)$ \\
\hline Low SES & 236 & 71.6 & $1.57(0.93-2.65)$ \\
\hline Trend & & & $P=0.11$ \\
\hline \multicolumn{4}{|l|}{ Urbanization } \\
\hline Urban & 418 & 67.5 & $1.0 \mathrm{REF}$ \\
\hline Large town & 62 & 79.0 & $1.72(0.86-3.45)$ \\
\hline Small town/rural & 58 & 70.7 & $1.32(0.68-2.58)$ \\
\hline Trend & & & $P=0.21$ \\
\hline \multicolumn{4}{|l|}{ Comorbid conditions } \\
\hline One or more & 199 & 75.9 & $2.14(1.39-3.32)$ \\
\hline None & 339 & 65.2 & $1.00 \mathrm{REF}$ \\
\hline \multicolumn{4}{|c|}{ 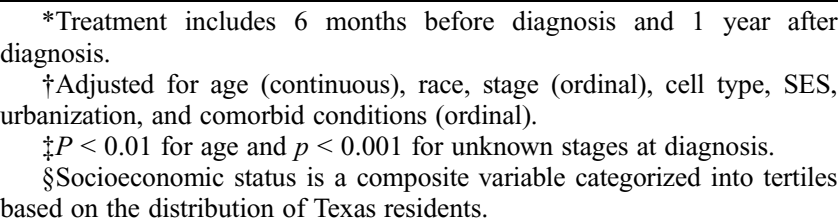 } \\
\hline
\end{tabular}

Among Medicare-eligible cervical cancer cases, those with an unknown stage at diagnosis were less likely to receive any type of treatment, whereas those with a comorbid condition and younger women were more likely to receive treatment (Table 2). We repeated the logistic analysis using multilevel modeling and found very similar effect estimates to those presented in Table 3, yet as anticipated, the confidence intervals (CIs) were less precise.

Table 3 presents our multivariable analyses from Cox proportional hazards modeling for all-cause survival and cervical cancer-specific survival separately. Models included individual attributes of the cancer case (eg, age, stage, cell type, race/ethnicity), neighborhood attributes of SES and urbanization, comorbid conditions, and treatment received.

\section{Demographic Factors}

Older women and those whose conditions were diagnosed at a late or unknown stage were significantly more likely to die and to die of cervical cancer. Although rural residence was not associated with an all-cause mortality, those living in large towns had almost a $90 \%$ increase in risk of dying of cervical cancer. Hispanic women with cervical cancer were less likely die relative to nonHispanic white or black women. The all-cause mortality rate was highest for non-Hispanic blacks (9.28 per 1000 woman-days) followed by non-Hispanic whites (7.50) and was lowest for Hispanic women (4.57). The same pattern was also true for cervical cancerspecific mortality.

\section{Comorbidity}

Women who had one or more comorbid conditions were $40 \%$ more likely to die when compared with those who did not have a comorbid condition after adjusting for all other factors. Similarly, having anemia at diagnosis was associated with a $59 \%$ increase in all-cause mortality and was elevated but not significant for cervical cancer-specific mortality when compared with women having no anemia noted in Medicare files.

\section{Treatment}

Receiving any form of treatment was associated with a reduced risk of dying but not with cervical cancer-specific mortality. Receiving surgery (cone biopsy or hysterectomy) alone or in combination with radiation or chemotherapy was associated with lower mortality rates relative to women not receiving treatment and adjusting for stage, cell type, and the remaining demographic factors. Although not presented in Table 3, increasing weeks to first treatment, independent of the type of treatment, was associated with slightly higher mortality (adjusted hazard ratio [aHR], 1.001-1.012; $P=0.02)$ yet not cervical cancer-specific mortality $(P=0.48)$. The number of radiation or chemotherapy claims was not associated with all-cause or cervical cancer-specific survival.

Because stage determines treatment options, we repeated the analysis for race/ethnicity and survival adjusting for age, cell type, SES, urbanization, comorbid conditions, and treatment by stage (data not presented in Table 3). Within each stage, Hispanic women remained less likely to die of cervical cancer relative to non-Hispanic white women (localized stage: aHR, 0.30; later stage: aHR, 0.51 ; unknown stage: aHR, 0.50).

We also used multilevel logistic regression modeling for these survival data and again noted similar effect estimates (relative risk vs hazard ratios) to those reported in Table 3 and much wider CIs.

\section{DISCUSSION}

Compared with non-Hispanic white women, Hispanic ethnicity was strongly associated with lower mortality rates in this cohort of elderly ( $>65$ years) women whose conditions were diagnosed with cervical cancer in Texas. This association held when simultaneously adjusting for age, stage, cell type, neighborhood SES, urbanization, presence of a comorbid condition, and treatment received. As anticipated, older women, those whose conditions were diagnosed at a late or unknown stage, and those with a nonsquamous cervical cancer were more likely to die. Adjusting for all factors, women receiving surgical treatment were less likely to die of cervical cancer. Although we adjusted for stage, it is likely that residual confounding may explain this finding because those requiring surgery alone have localized disease. Neighborhood SES and urbanization were not associated with survival.

We confirmed our finding of a lower mortality rate for Hispanic women after adjusting for SES and urban residence, both obtained from Census data, using multilevel logistic regression with mortality as the outcome ignoring time to this event for the 3-year 
TABLE 3. Multivariate predictors of survival for women aged 65 years and older whose conditions were diagnosed with cervical cancer and reported to the TCR from 1999 to 2001 using Medicare-linked treatment data

\begin{tabular}{|c|c|c|c|c|c|}
\hline \multirow[b]{2}{*}{ Demographic factors } & \multirow[b]{2}{*}{$\mathbf{n}^{*}$} & \multicolumn{2}{|c|}{ All-cause survival } & \multicolumn{2}{|c|}{ Cervical cancer-specific survival } \\
\hline & & Mortality rate $\dagger$ & Hazard ratio $\ddagger(95 \%$ CI $)$ & Mortality rate $\dagger$ & Hazard ratio $\$(95 \% \mathrm{CI})$ \\
\hline Age (continuous) & 491 & 6.92 & $1.05(1.03-1.06) \S$ & 3.56 & $1.04(1.02-1.07) \S$ \\
\hline \multicolumn{6}{|l|}{ Race/ethnicity } \\
\hline Non-Hispanic white & 270 & 7.50 & 1.0 REF & 3.97 & 1.0 REF \\
\hline Non-Hispanic black & 91 & 9.28 & $1.15(0.85-1.56)$ & 5.08 & $1.28(0.84-1.93)$ \\
\hline Hispanic & 130 & 4.57 & $0.57(0.41-0.80) \S$ & 1.99 & $0.48(0.29-0.79) \S$ \\
\hline \multicolumn{6}{|l|}{ Stage of diagnosis } \\
\hline Early stage & 179 & 3.59 & 1.0 REF & 1.49 & 1.0 REF \\
\hline Late stage & 219 & 10.86 & $2.72(1.98-3.73) \S$ & 6.07 & $2.88(1.83-4.55) \S$ \\
\hline Unknown stage & 93 & 7.63 & $2.00(1.38-2.91) \S$ & 3.88 & $2.36(1.38-4.04) \S$ \\
\hline \multicolumn{6}{|l|}{ Cell type } \\
\hline Nonsquamous & 177 & 8.30 & $1.30(0.98-1.73)$ & 3.66 & $1.13(0.74-1.72)$ \\
\hline Squamous & 314 & 6.56 & 1.0 REF & 3.53 & $1.00 \mathrm{REF}$ \\
\hline \multicolumn{6}{|l|}{ SES } \\
\hline High SES & 116 & 6.68 & 1.0 REF & 3.23 & 1.0 REF \\
\hline Mid SES & 154 & 6.50 & $0.96(0.68-1.35)$ & 3.61 & $0.98(0.61-1.56)$ \\
\hline Low SES & 221 & 7.33 & $1.17(0.84-1.63)$ & 3.70 & $1.12(0.70-1.80)$ \\
\hline Trend & & & $P=0.26$ & & $P=0.58$ \\
\hline \multicolumn{6}{|l|}{ Urbanization } \\
\hline Urban & 381 & 6.54 & 1.0 REF & 3.16 & 1.0 REF \\
\hline Large town & 55 & 8.48 & $1.36(0.92-2.0)$ & 5.66 & $1.88(1.15-3.08) \S$ \\
\hline Small town/rural & 55 & 8.33 & $1.32(0.90-1.93)$ & 4.65 & $1.46(0.86-2.45)$ \\
\hline Trend & & & $P=0.08$ & & $P=0.04$ \\
\hline \multicolumn{6}{|l|}{ Comorbid conditions } \\
\hline One or more & 177 & 8.35 & $1.40(1.08-2.81) \S$ & 3.49 & $0.96(0.75-1.22)$ \\
\hline None & 314 & 6.20 & 1.0 REF & 3.59 & 1.0 REF \\
\hline No. conditions & & & $1.25(1.07-1.47) \S$ & & $1.07(0.83-1.37)$ \\
\hline \multicolumn{6}{|l|}{ Anemia at diagnosis $\uparrow$} \\
\hline No & 441 & 6.34 & 1.0 REF & 3.20 & 1.0 REF \\
\hline Yes & 50 & 16.05 & $1.59(1.11-2.28) \S$ & 9.29 & $1.53(0.94-2.50)$ \\
\hline \multicolumn{6}{|l|}{ Treatment $\|$} \\
\hline No treatment & 128 & 8.81 & 1.0 REF & 3.37 & 1.0 REF \\
\hline Any treatment & 363 & 6.35 & $0.68(0.52-0.89) \S$ & 3.62 & $1.05(0.70--1.59)$ \\
\hline Days to first treatment & & & $P<0.01$ & & $P<0.01$ \\
\hline \multicolumn{6}{|l|}{ All treatments $\|$} \\
\hline No treatment & 129 & 8.81 & 1.0 REF $\S$ & 3.37 & 1.0 REF $\S$ \\
\hline Surgery/cone & 49 & 3.00 & $0.43(0.25-0.76) \S$ & 0.60 & $0.24(0.07-0.81) \S$ \\
\hline Radiation/chemotherapy & 76 & 12.41 & $1.10(0.74-1.60)$ & 7.31 & $1.63(0.95-2.79)$ \\
\hline Radiation and chemotherapy & 84 & 7.74 & $1.34(0.78-2.32)$ & 5.32 & $2.14(1.05-5.37) \S$ \\
\hline Radiation, chemotherapy, and surgery & 64 & 5.86 & $1.02(0.6--1.70)$ & 3.79 & $1.57(0.79-3.13)$ \\
\hline Radiation/chemotherapy and surgery & 90 & 4.51 & $0.52(0.33-0.81) \S$ & 2.14 & $0.65(0.33-1.22)$ \\
\hline No. chemotherapy & & & $0.98(0.95-1.02)$ & & $0.98(0.94-1.02)$ \\
\hline No. radiation & & & $0.98(0.96-1.00)$ & & $0.99(0.96-1.02)$ \\
\hline $\begin{array}{l}\text { *Excludes those with survival }=0 \text { days }(\mathrm{n}= \\
\dagger \text { Mortality rate calculated per } 10,000 \text { wome } \\
\text { †Adjusted for age (continuous), race, stage } \\
\text { number of cycles). } \\
\$ p<0.001 \text {. } \\
\text { \Anemia corresponds to the first case of do } \\
\| \text { Treatment includes } 6 \text { months before diagn }\end{array}$ & $\begin{array}{l}7) . \\
\text { lays. }\end{array}$ & 1), cell type, SES, ur & $\begin{array}{l}\text { banization, comorbid condition } \\
\text { re records; anemia at diagnosis }\end{array}$ & $\begin{array}{l}\text { (ordinal), and treatı } \\
\text { is within } 30 \text { days of }\end{array}$ & $\begin{array}{l}\text { ment (type, combination, and } \\
\text { cervical cancer diagnosis. }\end{array}$ \\
\hline
\end{tabular}


period. As anticipated, the CIs were wider, yet the relative risk estimates for all-cause and cervical cancer-specific mortality for Hispanic women relative to white women were $0.33(0.14-0.77)$ and $0.40(0.23-0.69)$, respectively. We present the hazard models because we lost follow-up data when we replaced logistic with Cox modeling.

Our finding that Hispanic women were less likely to die of cervical cancer contrasts with those of 2 published studies reporting that ethnicity was not an independent predictor of survival, ${ }^{8,17}$ yet is consistent with another large study conducted in Texas independent of age. ${ }^{19}$ What might explain this finding? In this Medicare-eligible population, Hispanic women were younger than non-Hispanic white women; however, Hispanic women did not differ from non-Hispanic whites in other factors predicting better survival such as early stage diagnosis, no comorbid conditions, squamous cell cancer, or treatment.

A social security number was required to merge the Medicare and TCR databases. Therefore, the population included in this analysis is not only older but also includes only US-born citizens or those with documentation. However, in analyses independent of documentation, a survival advantage for Hispanic women was still observed. ${ }^{19}$

Our finding of reduced risk of death among Hispanic women with cervical cancer is similar to that reported for prostate cancer survival ${ }^{46}$ in which prostate cancer cases identified through SEER were linked with Medicare data. Survival rates by ethnicity were adjusted for treatment, stage, age, and number of comorbid conditions. Greater social support, particularly from extended families, may explain this finding. Genetic differences may also play a role in explaining racial or ethnic differences in survival. ${ }^{46}$

A growing literature has addressed a "Hispanic paradox" in mortality that is most pronounced among Mexican Americans. ${ }^{47}$ Some evidence supports this paradox being explained by selective return migration toward the end of life, thus excluding those migrating from the numerator when estimating mortality rates. Improved survival for Hispanics may also be attributed to data quality and completeness issues. ${ }^{48,49}$ Medicare-NUDIMENT data, which avoid many problems inherent in vital statistics data, estimate mortality by race/ethnicity; however, analyses using this superior data source continue to reveal an attenuated but still significant advantage for Hispanics. ${ }^{47}$ Others conclude that whereas selective return migration and other data quality issues may explain some component of the Hispanic mortality paradox, other cultural factors including the "supportive aspects of Hispanic culture" should be empirically explored as explanatory factors in this phenomenon. ${ }^{50}$

Although we do not have data to evaluate the following possibility, racial/ethnic differences in smoking may explain the apparent Hispanic paradox observed in these data. Smoking, particularly in combination with high-risk human papillomavirus types, is etiologically linked to preinvasive and invasive cancer. ${ }^{51-54} \mathrm{An}$ emerging literature suggests that smoking may be linked to poor cervical cancer survival in 3 studies $^{55-57}$ of 5 reports. ${ }^{55-59}$ Prevalence of smoking differs dramatically by race/ethnicity in Texas. On the basis of 2006 Behavioral Risk Factor Surveillance System data for women 18 years and older, $38 \%$ of non-Hispanic white women smoke compared with $31 \%$ non-Hispanic black and $18 \%$ Hispanic women (Anna Vincent, Texas Department of State Health Services, personal communication). If smoking is associated with a 2-fold increase in mortality and we apply the proportion of Texas women who smoke to our data using external adjustment methods, ${ }^{60}$ Hispanic ethnicity is no longer significantly associated with a better survival relative to non-Hispanic white women $(P=0.35)$. Although we cannot empirically assess the aHR from our data, this observation suggests that ethnic differences in smoking prevalence may explain the observed Hispanic paradox in cervical cancer survival.
Our finding that non-Hispanic black race was not associated with mortality relative to whites among this Medicare population is consistent with those reported by Farley et $\mathrm{al}^{14}$ who used a large military population with significant racial diversity yet similar access to care. Farley et al found that race was not associated with survival and posited that equal access to medical care may remove the racial disparities in cancer incidence and survival. These findings contrast with a recent large SEER-based study reported by Singh et $\mathrm{al}^{20}$ who found a persistent association with lower SES and poorer survival for women of all ages. Further, we found a survival advantage for Hispanic women independent of SES. We hypothesize that the differences in study findings may be a result of our restriction to a sample with similar access to care (Medicareeligible women) and the ability to control for comorbid conditions and treatment received. Because $92 \%$ of cervical cancer cases had a Medicare claim and minority women were more likely to have a claim than white women, there is some evidence that women in this cohort had similar access to care.

Our finding that SES was not associated with survival after adjusting for age, race, and stage at diagnosis is consistent with 5 other studies, ${ }^{4,10,18,61,62}$ although contrasting 4 others. ${ }^{12,13,19,21}$ Further, lower SES was not associated with age, stage, or cell type; however, lower SES was associated with receiving any treatment within 365 days of diagnosis $(P<0.05)$. These patterns suggest that similar access to health care through Medicare eligibility may explain why SES had no observed effect on survival.

In contrast with a similar Medicare-SEER-linked analysis of survival, ${ }^{18}$ we did not exclude cervical cancer cases whose care was covered by primary private insurance. It is unlikely that we have differentially included those with private care from other insurance sources. Because we only have Medicare claims data and not other private insurance claims data, it is possible that we have underestimated treatment received; however, based on Medicare claims data, most women received treatment within 2 months. This finding suggests that at least the first course of treatment in included in the Medicare claims data.

Nonsquamous cervical cancers are not easily detected by Papanicolaou tests ${ }^{63,64}$ and subsequently are at greater risk for late stage diagnosis and poorer survival. We report here that women with nonsquamous carcinomas had decreased all-cause mortality but not cervical cancer-specific survival when adjusting for stage at diagnosis and treatment received; thus, neither stage nor treatment received explain this finding. Genetic differences in response to treatment by cell type may play a role that we cannot evaluate in this analysis.

Our finding that almost one quarter to one third of women aged 65 years and older received no treatment based on Medicare claims data is alarming. To explore potential issues with treatment data quality based on Medicare claims data, we compared treatment data from the TCR data. Rates of not receiving treatment based on TCR data $(\mathrm{n}=6320 ; 1998-2003)$ for women aged 65 years and older were $29 \%(n=1320)$ and $17 \%$ for women younger than 65 years. Among women aged 65 years and older in the TCR data, no significant differences in treatment rates by race/ethnicity were observed. Cancer registry data regarding treatment can also be incomplete, yet this comparison suggests that Medicare claims data indicating that approximately $30 \%$ of women aged 65 years and older with cervical cancer in Texas do not receive treatment is accurate. Our finding that ethnic differences in receipt of treatment based on claims data does suggest a problem with access to care in this Medicare-eligible population.

Several study limitations must be noted. Our sample size was relatively small, and it limits the power for analyses by stage. Because we are using existing data from Medicare and TCR, we are restricted to the data available. Having additional data to more 
fully characterize stage, tumor size, human papillomavirus type, smoking history, and other important predictors of survival was not available. Although we have included potential confounders in survival analyses models, residual confounding may still bias our estimates.

Because data to characterize individual SES were not avaiable, we used socioeconomic measures at the census tract level. Thus, a potential for misclassification exists for variables included in the TCR and Medicare files; however, these are not likely to be differential with respect to the outcome because data were collected before the outcome (time to mortality event). Further, the census tract is the smallest unit of analysis available for our SES composite variable.

This study adds to the existing literature $3,8,18,20,27,65,66$ on using cancer registry data linked with Medicare claims history in evaluating risk factors for survival among all elderly women whose conditions were diagnosed with cervical cancer. In contrast to hospital-based studies, registry-based studies are population-based and include all incident cervical cancer cases in the community. This study also adds to the existing literature as one of the few to address cervical cancer survival among older women in a multiethnic population. Finally, all women in the study have similar access to medical care based on age-eligibility to Medicare. However, our finding that ethnic differences in receipt of treatment and survival suggests that having Medicare coverage does not mean that older women with cervical cancer have similar access to care. Challenges remain in providing women with cervical cancer comprehensive health care coverage. Ethnic differences in social support, knowledge of treatment options, patient-provider communication skills, and other logistic barriers to receipt of care may also influence receipt of timely and appropriate treatment of cervical cancer.

\section{ACKNOWLEDGMENT}

Understanding disparities in cervical cancer survival (5R21CA114330), National Cancer Institute.

\section{REFERENCES}

1. Ries LAG, Harkins D, Krapcho M, et al. SEER Cancer Statistics Review, 1975-2003. Bethesda, MD: National Cancer Institute; 2006.

2. Newmann SJ, Garner EO. Social inequities along the cervical cancer continuum: a structured review. Cancer Causes Control. 63-70, 2005.

3. Howell EA, Chen YT, Concato J. Differences in cervical cancer mortality among black and white women. Obstet Gynecol. 1999;94:509-515.

4. Samelson EJ, Speers MA, Ferguson R, et al. Racial differences in cervical cancer mortality in Chicago. Am J Public Health. 1994;84: 1007-1009.

5. Bradley CJ, Given CW, Roberts C. Health care disparities and cervical cancer. Am J Public Health. 2004;94:2098-2103.

6. Jones WB, Shingleton HM, Russell A, et al. Patterns of care for invasive cervical cancer. Results of a national survey 1984-1990. Cancer. 1995;76:1934-1947.

7. Greenwald HP, Borgatta EF, McCorkle R, et al. Explaining reduced cancer survival among the disadvantaged. Milbank Q. 1996;74: 215-238.

8. Brewster WR. Young age as a prognostic factor in cervical cancer: results of a population-based study. Am J Obstet Gynecol. 1999;180: 1464-1467.

9. Brooks SE, Baquet CR, Gardner JF, et al. Cervical cancer-the impact of clinical presentation, health and race on survival. $J$ Assoc Acad Minor Phys. 2000;11:55-59.

10. Shelton D, Paturzo D, Flannery J, et al. Race, stage of disease, and survival with cervical cancer. Ethn Dis. 1992;2:47-54

11. Thoms WW, Unger EJ, Johnson PR, et al. Cervical cancer survival in a high risk urban population. Cancer. 1995;76:2518-2523.
12. Mundt AJ, Connell PP, Campbell T, et al. Race and clinical outcome in patients with carcinoma of the uterine cervix treated with radiation therapy. Gynecol Oncol. 1998;7:151-158.

13. Morgan MA, Behbakht K, Benjamin I, et al. Racial differences in survival from gynecologic cancer. Obstet Gynecol. 1996;88: 914-918.

14. Farley JH, Hines JF, Taylor RR, et al. Equal care ensures equal survival for African-American women with cervical carcinoma. Cancer. 2001;91:869-873.

15. Grigsby PW, Hall-Daniels L, Baker S, et al. Comparison of clinical outcome in black and white women treated with radiotherapy for cervical carcinoma. Gynecol Oncol. 2000;79:357-361.

16. Ragland KE, Selvin S, Merrill DW. Black-white differences in stage-specific cancer survival: analysis of seven selected sites. Am J Epidemiol. 1991;133:672-682.

17. Schorge JO, Lea JS, Garner EO, et al. Cervical adenocarcinoma survival among Hispanic and white women: a multicenter cohort study. Am J Obstet Gynecol. 2003;188:640-644.

18. Coker AL, Du XL, Fang S, et al. Socioeconomic status and cervical cancer survival among older women: findings from the SEER-Medicare linked data cohorts. Gynecol Oncol. 2006;102:278-284.

19. Eggleston KS, Coker AL, Williams M, et al. Socioeconomic status as a predictor of cervical cancer survival in Texas, 1995-2001. $J$ Womens Health (Larchmt). 2006;15:941-951.

20. Singh GK, Miller BA, Hankey BF, et al. Persistent area socioeconomic disparities in U.S. incidence of cervical cancer, mortality, stage, and survival, 1975-2000. Cancer. 2004;101: 1051-1057.

21. Johnson MG. Socioeconomic differences in cervical cancer survival among South Carolina women. In: Epidemiology and Biostatistics. Columbia, SC: University of South Carolina; 2003.

22. Sawaya GF, Sung HY, Kearney KA, et al. Advancing age and cervical cancer screening and prognosis. J Am Geriatr Soc. 2001;49: 1499-1504.

23. Meanwell CA, Kelly KA, Wilson S, et al. Young age as a prognostic factor in cervical cancer: Analysis of population based data from 10,022 cases. Br Med J. 1988;296:386-391.

24. Wright JD, Gibb RK, Geevarghese S, et al. Cervical carcinoma in the elderly. Cancer. 2004;103:85-91.

25. Chapman GW. Survival of advanced age females with cervical carcinoma. Gynecol Oncol. 1992;46:287-291.

26. Brun JL, Stoven-Camou D, Trouette R, et al. Survival and prognosis of women with invasive cervical cancer according to age. Gynecol Oncol. 2003;91:395-401.

27. Kosary CL. FIGO stage, histology, histologic grade, age and race as prognostic factors in determining survival for cancers of the female gynecological system: an analysis of 1973-87 SEER cases of cancers of the endometrium, cervix , ovary, vulva and vagina. Semin Surg Oncol. 1994;10:31-46.

28. Russell JM, Blair V, Hunter RD. Cervical carcinoma: prognosis in younger patients. Br Med J. 1987;295:300-303.

29. Spanos WJ, King A, Keeney E, et al. Age as a prognostic factor in carcinoma of the cervix. Gynecol Oncol. 1989;35:66-68.

30. de Rijke JM, van der Putten HW, Lutgens LC, et al. Age-specific differences in treatment and survival of patients with cervical cancer in the southeast of the Netherlands. Eur J Cancer. 2002;38:2041-2017.

31. Serur E, Fruchter RG, Maiman M, et al. Age, substance abuse, and survival of patients with cervical carcinoma. Cancer. 1995;75: 2530-2538

32. Minagawa Y, Kigawa J, Itamochi H, et al. The outcome of radiation therapy in elderly patients with advanced cervical cancer. Int J Gynaecol Obstet. 1997;58:305-309.

33. Prempree T, Patanaphan V, Sewchand W, et al. The influence of patients' age and tumor grade on the prognosis of carcinoma of the cervix. Cancer. 1983;51:1464-1771.

34. Delaloye JF, Pampallaona S, Coucke PA, et al. Younger age as a bad prognostic factor in patients with carcinoma of the cervix. Eur J Obstet Gynecol Reprod Biol. 1996;64:201-205.

35. Leveque J, Laurent JF, Burtin F, et al. Prognostic factors of the 
uterine cervix adenocarcinoma. Eur J Obstet Gynecol Reprod Biol. 1998;80:209-214.

36. Ishikawa $\mathrm{H}$, Nakanishi $\mathrm{T}$, Inoue $\mathrm{T}$, et al. Prognostic factors of adenocarcinoma of the uterine cervix. Gynecol Oncol. 1999;73:42-46.

37. Diez Roux AV, Kiefe CI, Jacobs DR, et al. Area characteristics and individual level socioeconomic position indicators in three population based epidemiologic studies. Ann Epidemiol. 2001;11:395.

38. Robert SA, Strombom I, Tretntham-Dietz A, et al. Socioeconomic risk factors for breast cancer. Distinguishing individual- and community-level effects. Epidemiology. 2004;15:442.

39. Sanderson M, Coker AL, Perez A, et al. A multilevel analysis of socioeconomic status and prostate cancer risk. Ann Epidemiol. 2006;16:901-917.

40. Rural Health Research Center. Rural-Urban Commuting Area Codes. Seattle, WA: University of Washington, Rural Health Research Center; 2006. http://depts.washington.edu/uwruca/rucal/ruca_definitionchart.html.

41. Rural Health Research Center. RUCA Data: Using RUCA Data. Seattle, WA: University of Washington, Rural Health Research Center; 2006. http://depts.washington.edu/uwruca/rucal/ruca_definitionchart.html.

42. Du XL, Chan W, Giordano S, et al. Variation in modes of chemotherapy administration for breast cancer and association with hospitalization for chemotherapy-related toxicity. Cancer. 2005; 104:913-924.

43. Charlson ME, Pompei P, Ales KL, et al. A new method of classifying prognostic comorbidity in longitudinal studies: development and validation. J Chronic Dis. 1987;40:373-383.

44. Melfi C, Holleman E, Arthur D, et al. Selecting a patient characteristics index for the prediction of medical outcomes using administrative claims data. J Clin Epidemiol. 1995;48:917-926.

45. Fleming ST, Tastogi A, Dmitrienko A, et al. A comprehensive prognostic index to predict survival based on multiple comorbidities: a focus on breast cancer. Med Care. 1999;37:601-614.

46. Du XL, Fang S, Coker AL, et al. Racial disparity and socioeconomic status in association with survival in older men with local/regional stage prostate cancer: findings from a large community-based cohort. Cancer. 2006;106:1276-1285.

47. Markides KS, Eschbach K. Aging, migration, and mortality: current status of search on the Hispanic paradox. J Gerontol B Psychol Sci Soc Sci. 2005;60:68-75.

48. Patel KV, Eschbach K, Ray LA, et al. Evaluation of mortality data for older Mexican Americans: implications of the Hispanic paradox. Am J Epidemiol. 2004;159:707-715.

49. Smith DP, Bradshaw BS. Rethinking the Hispanic paradox: death rates and life expectancy for US non-Hispanic white and Hispanic populations. Am J Public Health. 2006;96:1686-1692.

50. Franzini L, Ribble JC, Keddie AM. Understanding the Hispanic paradox. Ethn Dis. 2001;11:496-518.

51. Herrero R, Brinton LA, Reeves WC, et al. Invasive cervical cancer and smoking in Latin America. J Natl Cancer Inst. 1989;81:205-211.
52. Castle PE, Wacholder S, Lorincz A, et al. A prospective study of high-grade cervical neoplasia risk among human papillomavirus-infected women. J Natl Cancer Inst. 2002;94: 1406-1414.

53. IARC Working Group on the Evaluation of Carcinogenic Risks to Humans. Volume 83: Tobacco smoke and involuntary smoking. IACR Publications, Lyon, France, 2004.

54. Tsai HT, Tsai YM, Yang SF, et al. Lifetime cigarette smoke and second-hand smoke and cervical intraepithelial neoplasm - a community-based case-control study. Gynecol Oncol. 2007;105: $181-188$.

55. Wright JD, Li J, Gerhard DS, et al. Human papillomavirus type and tobacco use as predictors of survival in early stage cervical carcinoma. Gynecol Oncol. 2005;98:84-91.

56. Waggoner SE, Darcy KM, Fuhrman B, et al. Association between cigarette smoking and prognosis in locally advanced cervical carcinoma treated with chemoradiation: a gynecologic oncology group study. Gynecol Oncol. 2006;103:853-858.

57. Kucera H, Enzelsberger H, Eppel W, et al. [Effect of nicotine abuse on treatment results in primary irradiated cervical cancer]. Geburtshilfe Frauenheilkd. 1986;46:388-390.

58. Fyles A, Voduc D, Syed A, et al. The effect of smoking on tumor oxygenation and treatment outcome in cervical cancer. Clin Oncol. 2002;14:442-446.

59. Serur E, Fruchter RG, Maiman M, et al. Age, substance abuse, and survival of patients with cervical carcinoma. Cancer. 1995;75: 2530-2538.

60. Rothman KJ, Greenland S. Modern Epidemiology. 2nd ed. Philadelphia, PA: Lippincott Williams \& Wilkins; 1998.

61. Greenwald HP, Polissar NL, Dayal HH. Detecting survival effects of socioeconomic status: problems in the use of aggregate measures. J Clin Epidemiol. 1994;47:903-909.

62. Murphy M, Goldblatt P, Thornton-Jones H, et al. Survival among women with cancer of the uterine cervix: influence of marital status and social class. J Epidemiol Comm Health. 1990;44:293-296.

63. Krane JF, Granter SR, Trask CE, et al. Papanicolaou smear sensitivity for the detection of adenocarcinoma of the cervix: a study of 49 cases. Cancer. 2001;93:8-15.

64. Renshaw AA, Mody DR, Lozano RL, et al. Detection of adenocarcinoma in situ of the cervix in Papanicolaou tests: comparison of diagnostic accuracy with other high-grade lesions. Arch Pathol Lab Med. 2004;128:153-157.

65. Liu T, Wang X, Waterbor JW, et al. Relationships between socioeconomic status and race-specific cervical cancer incidence in the United States, 1973-1992. J Health Care Poor Underserved. 1998;9:420-432.

66. Mitchell JBP, McCormack LA. Time trends in late-stage diagnosis of cervical cancer: differences by race/ethnicity and income. Med Care. 1997;35:1220-1224. 